chapters. I counted half a dozen references which were reproduced in triplicate and many papers that were quoted twice by different authors. Perhaps it emphasizes the rather specialized nature of the book. There are several typographical errors, in particular the dose of total body irradiation is given as $100 \mathrm{rad}$ instead of $1000 \mathrm{rad}$ in the table on page 136. There were numerous misprints of authors' names and initials throughout the references. I think it is a pity that Dr Geary did not think it worth-while including a chapter on other approaches to treatment in this disease: the use of stimulators such as androgens, lithium, etiocholanolone and PHA merit some attention since they point to methods other than immunosuppression and bone marrow transplantation whereby aplastic bone marrow can be stimulated to regenerate.

All in all, this is an up-to-date and comprehensive review of a fascinating subject which provides good reading and an excellent source of references for the haematologist or physician involved with the investigation and management of aplasia and its related syndromes. The book makes good reading for Final M.R.C.Path. at a price which is not unreasonable these days.

\section{Biochemical Disorders of the Skeleton}

By Roger Smith. Postgraduate Orthopaedics Series. Series Editor: A. GrahaM APLeY. Pp. $x+293$, illustrated. Butterworths, London, 1979. $£ 19.50$.

This book is primarily intended for orthopaedic surgeons and others involved in the clinical and laboratory techniques and management of bone disease. The author correctly notes that it is not intended as a text on 'metabolic bone disease' and rather disarmingly expresses the hope that it will be of help to orthopaedic surgeons who find the subject made 'needlessly complex by physicians'.

The text is concise, perhaps reflecting the series of postgraduate lectures on which it is based. The first 2 chapters present an up-to-date review of bone physiology and the diagnosis of metabolic bone disorders. Subsequent sections are devoted to the topics of osteomalacia, osteoporosis, parathyroids in relation to bone disease and ectopic mineralization. The remainder deal with disease entities including Paget's disease, osteogenesis imperfecta, Marfan's and related syndromes and the mucopolysaccharidoses. The final 2 chapters are concerned with a miscellany of rarer conditions and recent advances respectively. The book is adequately illustrated although many of the diagrams will be familiar to those already working in the field. It is, however, extremely well provided with selected, up-to-date references.

The book can be recommended as a useful introduction to the subject, particularly for those preparing for postgraduate examinations. It would also provide a useful and readable review for surgeons and other clinicians in the field. In spite of its price, it will be a useful addition to postgraduate libraries.

\section{A Colour Atlas of Liver Disease}

By Sheila Sherlock and John A. Summerfield. Pp. 272, illustrated. Wolfe Medical Publications, London, 1979. £18.00.

This is an outstanding collection of more than 500 illustrations encompassing the whole spectrum of liver disease. Rare diseases, paediatric and tropical diseases are all covered. In addition to the many clinical photographs, relevant histology, isotope scans, CT scans, ultrasounds, X-rays, endoscopies and laparoscopies are all included. The quality of the illustrations is generally very good although some of the X-rays have not reproduced well. The legends to the illustrations are particularly useful, the reader often being reminded of the causes and pathophysiology of the abnormality. The book will undoubtedly be of value to any physician with an interest in liver disease.

\section{Controlling the Smoking Epidemic}

Report of the WHO Expert Committee on Smoking Control. WHO Technical Report Series no. 636. Pp. 87, illustrated. World Health Organization, Geneva, 1979. Sw. fr. 9.00.

This excellent small monograph is the report of the WHO Expert Committee on Smoking Control. It deals with the harmful health consequences of smoking, particularly emphasizing the statistics in relation to ischaemic heart disease, chronic bronchitis and emphysema and neoplasia of the lung, and the effects of smoking on children and young people. The socio-economic implications of tobacco smoking entails huge economic losses which constitute a sizable burden to every national economy. Of particular interest are the recommended strategies for controlling the smoking epidemic and also monitoring the smoking problem.

This is an excellent monograph and should be compulsory reading for all doctors and smokers. It is very reasonably priced and will, it is hoped, enjoy a wide circulation.

\section{Human Growth}

Edited by Frank Falkner and J. M. TANner. Vol. Principles and Prenatal Growth. Pp. xix +634 , illustrateo

Vol. 2. Postnatal Growth. Pp. xviii +634 , illustrated Baillière Tindall, London, 1978. £24.75 per vol.

The phenomenon of growth has intrigued physicians ane laymen alike for centuries and yet it is only recently that itg study has become the subject of major interdisciplinare scientific endeavour. Few attempts have been made to relate the wide range of fields of investigation to each othes ranging as they do from prenatal to adolescent life, fron experimental biology to clinical medicine and from the growth of cells in individual tissues to the complex mechanisms governing growth and maturation of the intact organism.

This series of 3 volumes, of which the first 2 have now been published, are a remarkable attempt to remedy this gap in the literature. They contain contributions from nearly 70 distinguished workers under the editorship of 2 acknowledged experts. The first volume is concerned with the principles of human developmental biology, the application of biometrical methods, the genetics of growth and growth in the prenatal period. The second volume is devoted to postnatal growth from infancy to adolescence, with sections on anthropometry, hormonal and compositional changes, dentition, and the growth of low birth weight infants. Each volume is well illustrated and referenced and is separately indexed.

This series will provide a valuable reference source for research workers, obstetricians, paediatricians and others involved in child health and development. The price is a little high but not excessive for what may well become a standard work.

The Investigation of the Surgical Patient

By F. G. Smiddy. Pp. $x+262$, illustrated. Edward Arnold, London, 1979. £17.50.

Geoffrey Smiddy is a Leeds surgeon, born and bred in the Moynihan tradition and continues to carry his torch as a magnificent surgical teacher. In this, his third major text- 
book, he takes the common presenting symptoms that we see every day in the general surgical clinics and the emergency rooms - dysphagia, diarrhoea, jaundice, gastrointestinal bleeding and acute abdominal pain, for example and describes their investigation. Being a good clinician, he naturally starts with the clinical study of the patient and then guides us through the complexities, advantages, disadvantages and positive dangers of the almost overwhelming array of modern laboratory and radiological investigations which are now available to us. There are, in addition, chapters on the investigation of fluid and electrolyte balance and postoperative complications which are particularly valuable. Computerized axial tomography (CAT) scanning, which is not generally available yet in this country, is only touched upon in this edition but ultrasound is considered fully and is well illustrated. The text is easy to read, the illustrations clear and the references up to date so that this volume will certainly come to the aid of everyone in the surgical team from chief to house surgeon.

I must confess that I am a biased observer when it comes to reviewing this volume, since it was my privilege and pleasure to read it through from cover to cover while it was still in manuscript form. I certainly found that I had benefited enormously from studying the text with care and I can warmly commend it to my colleagues in surgery.

\section{Medical Acid-Base Balance. The Basic Principles}

By Michael L. G. Gardner. Pp. 125, illustrated, limp cover. Baillière Tindall, London, 1978. £3.95.

There are many books dealing with this topic and it is difficult to see how this one has anything new to offer. It is also difficult to see for whom the book is written. It is essentially an account of acid-base physiology, but far too detailed for a preclinical student. On the other hand clinical diseases in which acid-base balance is abnormal are hardly mentioned. An irritating feature is the repeated references to later sections, giving the reader the impression that he will have to read the book at least twice in order to understand it. Despite these criticisms the text is clearly written, and useful summaries for chapters are given in the appendix.

\section{Reproduction}

British Medical Bulletin Vol. 35, no. 2, May 1979. Scientific Editor, R. V. SHORT. Pp. 112, illustrated. Medical Department, British Council, London, 1979. $£ 5.00$.

The current issue of the British Medical Bulletin, devoted to the subject of reproductive biology (in the words of the Editor 'the science of the transmission of life') is superb. It is also important, for if we are not all to perish we need to know how to limit the transmission of life in our own species and to promote it in those we rely on to feed us. Professor Short points out in his introduction that we cannot rely on putting into practice our currently available information because in reality we lack the kind of basic information that is necessary. But basic information needs basic research and that means the Western 'high technology' approach. And that, of course, is expensive. Professor Short asks whether the highly developed nations of the West will take up the challenge. 'Not on present evidence' seems to be the answer of Dr Aitken who, writing on contraceptive research and development, points out that since 1974 Governmental funding for research in this field has declined in most of the industrialized nations.

That is a depressing introduction to this issue of the British Medical Bulletin but I hope it will not deter readers. The contributors are all internationally recognized experts who have managed to make their information easily understandable and have also transmitted their enthusiasm for their subjects. Obviously a volume like this will be concerned, inter alia, with hormones and there are excellent accounts of the endocrinology of the testis, the ovary, of lactation and lactational infertility, of parturition and of infertility. There are also accounts of meiosis in oöcytes, of chromosomal abnormalities in infertility and of the genetics of sex determination and differentiation. The control of early development, fetal growth and prostaglandins are also discussed. At $£ 5$, this issue of the British Medical Bulletin is incredible value for money.

\section{Surgical Review 1}

Edited by J. S. P. Lumley and J. L. Craven. Pp. viii +407 , illustrated. Pitman Medical, London, 1979. £9.95.

With increasing specialization, there is no doubt that surgeons are experiencing more and more difficulty in keeping abreast of the broad front of surgical progress. Yet few surgeons can be disinterested in the advances which are being made in other branches of their science and art. Indeed, the cross-fertilization between the specialities is a constant source of production of valuable mutations. The stapling machine produced for oesophageal anastomoses may prove just the instrument that the proctologist is looking for in order to carry out a low anterior resection of the rectum.

One way to overcome the problem is to ask a group of enthusiastic specialists to review their own particular fields of interest and to ask them to do this in a lively and perhaps somewhat controversial way. The editors of this volume are to be congratulated on their success. The 22 chapters range over oncology, orthopaedics, vascular surgery, urology and even include an economist's point of view on the costs and benefits of surgery. Although principally aimed at candidates working for their higher surgical diplomas - for which it is eminently suitable - this is certainly a book that can be read with both gain and pleasure by established surgeons who seek an interesting and up-to-date account of surgical progress. We look forward to further reviews in this series at the same excellent standard.

\section{A Textbook of Surgical Pathology}

By Sir Charles Illingworth and the late Bruce J. Dick. 12th edn, Pp. 357, illustrated. Churchill Livingstone, Edinburgh, London and New York, 1979. £15.00.

'Illingworth and Dick' has been a friend of medical students and FRCS candidates for the past 47 years, and through 12 editions and numerous reprints. This is surely a record in medical publishing as throughout that time it has remained under the facile pen of its still young senior author, now emeritus Professor of Surgery in the University of Glasgow. His co-author, Bruce Dick, sadly died in 1967. Sir Charles has always had the praiseworthy facility of being able to speak and to write in clear, precise English. His textbook is a model of brevity. As an example, the subject of Immunity is brilliantly covered in seven and a half pages which give a clear and up-to-date summary of this rapidly advancing field. The illustrations - of macroscopic, microscopic and radiological appearances - are profuse and clear, and there are sufficient references for further reading to enlarge on the major topics.

After opening chapters on response to injury, immunity, wound infection and tumours, succeeding sections cover regional pathology and include a final chapter on gynaecology. As befits the life-time interest of Sir Charles, the section on stomach and duodenum is particularly good.

This attractive volume is warmly commended to students 